\title{
Caracterización biológica y molecular de cepas de Panstrongylus sp. nativas del Perú
}

\section{Biological and molecular characterization of Panstrongylus sp. native of Peru}

\author{
Cesar Hugo Jerí Apaza ${ }^{1, a}$, Hila Solis Acosta ${ }^{1, b}$ \\ ${ }^{1}$ Instituto de Medicina Tropical Daniel A. Carrión, Facultad de Medicina, Universidad Nacional Mayor de San Marcos. Lima, Perú. \\ ${ }^{a}$ Bióloga, ORCID: https://orcid.org/0000-0002-4610-7570
}

An Fac med. 2020;81(2):186-9. / DOI: https://doi.org/10.15381/anales.v81i2.18157.

Correspondencia:

Cesar Jerí Apazacesa

Jeri@yahoo.es

Recibido: 23 de diciembre 2019

Aceptado: 29 de mayo 2020

Publicación en línea: 30 de junio 2020

Conflictos de interés: El autor declara no tener conflictos de interés.

Fuente de financiamiento: Vicerrectorado de Investigación y Posgrado, Universidad Nacional Mayor de San Marcos. Proyecto CONCON 2015.

Citar como: Jerí C, Solis H. Caracterización biológica y molecular de cepas de Panstrongylus sp. nativas del Perú. An Fac med. 2020;81(2):1869. DOI: https://doi.org/10.15381/anales. v81i2.18157.

\section{Resumen}

Objetivo. Determinar las características biológicas y moleculares de las cepas de Panstrongylus sp. nativas del norte del Perú. Métodos. Estudio observacional, descriptivo. Se utilizó material biológico procedente de 5 diferentes regiones del norte del Perú, y por muestreo intencional se seleccionó una muestra de 50 especimenes. Para la caracterización de los especimenes a nivel molecular, se usó el marcador ITS-2 del ADN ribosomal, mediante la técnica del PCR. Resultados. El 100\% de las muestras fueron clasificadas como Panstrongylus herreri. A nivel molecular se observaron 3 patrones diferentes de la banda ITS-2: $960 \mathrm{pb}, 800 \mathrm{pb}$ y $750 \mathrm{pb}$. Conclusión. 100\% de las muestras fueron Panstrongylus herreri, capturados en ambientes intradomiciliarios de regiones del norte del Perú, con un patrón de ITS-2.

Palabras clave: Biologia Molecular; Panstrongylus; Enfermedad de Chagas; Perú (fuente: DeCS BIREME).

Abstract

Objective. To determine the biological and molecular characteristics of the Panstrongylus sp. native to northern Peru. Methods. Observational, descriptive study. Biological material from 5 different regions of northern Peru was used, and a sample of 50 specimens was selected by intentional sampling. For the characterization of the specimens at the molecular level, the ITS-2 marker of ribosomal DNA was used, using the PCR technique. Results. $100 \%$ of the samples were classified as Panstrongylus herreri. At the molecular level, 3 different patterns of the ITS-2 band were observed: $960 \mathrm{bp}, 800 \mathrm{bp}$ and $750 \mathrm{bp}$. Conclusion. $100 \%$ of the samples were Panstrongylus herreri, captured in intra-household environments in northern regions of Peru, with an ITS-2 pattern.

Keywords: Molecular Biology; Panstrongylus; Chagas Disease; Peru (source: MeSH NLM). 


\section{INTRODUCCIÓN}

Los triatominos son insectos hematófagos pertenecientes a la familia Reduvidae y de la subfamilia Triatominae. Tienen importancia epidemiológica porque un grupo de ellos transmiten el protozoario Trypanosoma cruzi, el agente etiológico de tripanosomiasis americana, conocida como la enfermedad de Chagas. En el norte del Perú existe una gran diversidad de triatominos que cumplen el rol de vector para la transmisión de parásito Tripanosoma cruzi ${ }^{(1,2,3,4)}$ y uno de ellos, el más importante, es el triatomino Panstrongylus herreri, por encontrarse en mayor porcentaje (más del 90\%) en los estudios de campo realizados en la zona norte o nororiente del país, encontrando la mayoría de sus estadios en áreas intradomiciliarias ${ }^{(5)}$; así por ejemplo, se ha reportado la presencia de este triatomino en los departamentos de Piura, Cajamarca y Amazonas ${ }^{(10)}$.

Para la clasificación de los vectores de los distintos parásitos, la taxonomía es una herramienta base ${ }^{(6)}$; sin embargo, en los últimos años se ha complementado con herramientas moleculares para realizar un análisis más exacto y rápido. Marcilla en el 2001 utilizó la región del segundo separador transcrito interno de ADN ribosomal (ITS-2) como marcador molecular para poder resolver relaciones existentes entre distintas poblaciones de triatominos. Esto permitió diferenciar a los triatominos por el tamaño (número de pares de bases) de amplificación de dicha región ${ }^{(7)}$. Luego, en 2002 Marcilla realizó un estudio con los distintos géneros de Panstrongylus indicando que Panstrongylus herreri y Panstrongylus lignarus son la misma especie. Estos estudios apoyan que dichas regiones de ADNr son muy importantes para estudios filogenéticos y a varios niveles taxonómicos ${ }^{(8)}$.

En el Perú, los estudios moleculares por PCR en triatominos, sobre todo en la región norte del país, son escasos. El único realizado fue en el año 2008 por Ancca, quien realizó un estudio en los departamentos de Cajamarca y Amazonas, reportando la presencia de Panstrongylus herreri infectados por Trypanosoma cruzi, y encontrando una amplificación de la región ITS-2 de 960 pares de bases (pb) ${ }^{(9)}$.
Si bien se ha reportado la presencia de este vector en zonas donde antes no se había reportado ${ }^{(5,10)}$, es aún desconocida su presencia en otras áreas geográficas de nuestro país. Así, el objetivo de la presente investigación fue determinar las características biológicas y moleculares de las cepas de Panstrongylus sp. nativas del Perú, reportadas en distintas regiones del Perú. Además de caracterizarlas y agruparlas genéticamente para su mejor estudio y control, utilizando el marcador molecular ITS-2 del ADN ribosomal, mediante la técnica del PCR ${ }^{(11,12,)}$.

\section{MÉTODOS}

Se realizó un estudio observacional descriptivo, en los departamentos de Trujillo (Trujillo), Amazonas (Bagua), Cajamarca (Cajabamba, Chota), y Ucayali (Pucallpa- Campo verde). La recolección de vectores se realizó desde setiembre 2014 a abril de 2015; y la identificación molecular entre agosto 2016 a diciembre 2019.

\section{Recolección de triatominos}

Se realizó la colección de muestras de vectores según el protocolo realizado por Solís et al. ${ }^{(4)}$ donde la colecta de especímenes se realiza principalmente en la mañana en zonas intradomiciliarias, recolectando manualmente en bolsas de plástico para luego ser trasladados a frascos de boca ancha cubiertos con un tul para mantenerlos vivos, rotulados según fecha de captura, procedencia y en qué ambiente se encontraron. Las muestras obtenidas fueron remitidas al Laboratorio de Serología y Bioquímica Parasitaria del Instituto de Medicina Tropical Daniel A. Carrión de la Facultad de Medicina de la Universidad Nacional Mayor de San Marcos. Todos los especímenes de triatominos (ninfas y/o adultos hembras y machos) fueron identificados según la clave dicotómica de Lent \& Wygodzinsky ${ }^{(13)}$. Los triatominos colectados se mantuvieron en frascos de vidrio cubiertos con tul para una adecuada oxigenación y facilitar su supervivencia; asimismo, fueron alimentados con sangre de aves (pollos) hasta el momento de la extracción de ADN.

\section{Población y muestra}

La población la conformó el material biológico recolectado, que consistió en especímenes de Panstrongylus sp. procedentes de las regiones donde se hizo la recolección. Por medio de muestreo intencional, se seleccionó una muestra de 50 especímenes: 10 especímenes de cada región.

\section{Identificación biológica y molecular}

Se utilizó como técnica la observación, y como instrumento la lista de verificación. La observación se hizo mediante la caracterización de los especímenes de Panstrongylus sp. para su agrupación taxonómica, y para su identificación molecular se utilizó el marcador molecular ITS-2 del ADN ribosomal para su amplificación mediante la técnica de PCR ${ }^{(8,9,11,12)}$

El procedimiento de extracción de ADN se realizó entre los meses de diciembre 2015 y agosto del 2016. El ADN genómico del vector se obtuvo a partir de las patas de cada insecto, utilizando protocolos realizados por Ancca ${ }^{(9)}$ y Fraga ${ }^{(14)}$. La extracción del ADN genómico se realizó utilizando el kit DNeasy tissue handbook de QUIAGEN ${ }^{\circledR}$ con un ajuste de resuspensión final de $200 \mu \mathrm{L}$.

Luego de la extracción de ADN se realizó la amplificación de la región ITS-2 del ADNr con los primers específicos ${ }^{(8)}$.

\section{Síntesis de primers}

Se sintetizaron los primers (cebadores/ iniciadores) para la amplificación de la región ITS-2 del ADNr. Los primers que se utilizaron fueron los siguientes: 5.8T (5'CATAGC GGT GGA TCA CTC GG) y $28 \mathrm{~T}$ (5'GCACTAT CAA GC A ACA CGA CTC $)^{(8,9)}$.

\section{Estandarización del PCR}

Para realizar el PCR se consideró la concentración final de la reacción de PCR fue de $1 \mathrm{X}$ para el buffer de reacción de Taq polimerasa, 4mM de ClMg2 (Invitrogen $\left.{ }^{\circledR}\right), 2$ mM para los dNTPs, $1 \mu \mathrm{M}$ para cada uno de los primers y $1 \cup{ }^{\circledR} T a q$ DNA Polymerase (Invitrogen ${ }^{\circledR}$ ).

Las condiciones para el termociclador fueron: inicio $92^{\circ} \mathrm{C} \times 2$ minutos; denaturación $92^{\circ} \mathrm{C}$ por 30 segundos; alineamiento $55^{\circ} \mathrm{C}$ por 30 segundos; extensión $72^{\circ} \mathrm{C}$ por 40 segundos. Este proceso se llevó a cabo usando 33 ciclos, luego se finalizó a $72^{\circ} \mathrm{C}$ por 2 minutos. Los productos fueron visualizados mediante un 
gel de agarosa al 1\% y teñidos con SYBR green utilizándose el marcador de peso molecular $100 \mathrm{pb}$.

\section{RESULTADOS}

Se observaron especímenes de Panstrongylus sp. ninfas, adultos hembras o machos. Todos fueron identificados según la clave dicotómica de Lent ${ }^{(13)}$ y Wygodzinsky ${ }^{(15)}$, y comparados con la clave de Elliot ${ }^{(6)}$. El 100\% de especímenes evaluados correspondieron morfométricamente a la especie Panstrongylus herreri.

Respecto a la caracterización molecular se observó la amplificación de una banda de interés: ITS-2. Las muestras se corrieron por duplicado, además de colocar dos controles negativos a fin de verificar que no había contaminación al momento de preparar las soluciones para el PCR. En las 5 zonas de recolección de muestras, se observaron 3 patrones diferentes de ITS-2 en las muestras de Panstrongylus herreri. Las muestras de la zona de Trujillo y Ucayali presentaron una banda de ITS-2 de 960pb, las muestras de las zonas de Cajamarca y Cajabamba presentaron una banda ITS-2 de 800pb, y las muestras de la región de Bagua presentaron una banda de 750pb (Figura 1).

\section{DISCUSIÓN}

El género Panstrongylus ha sido localizado con denominaciones sinónimas en diversas partes del Perú. Previamente se estableció la presencia del vector en el norte del Perú, predominantemente en los departamentos de Cajamarca y Amazonas, pero con estos resultados se puede afirmar la presencia de Panstrongylus herreri en los departamentos de Trujillo y Ucayali.

Mediante la caracterización molecular se pudo comprobar que la banda de ITS-2 de Panstrongylus herreri en Perú presentó tres patrones: 960pb (Trujillo, Ucayali); $800 p b$ (Cajamarca, Cajabamba) y 750pb (Bagua). Ancca y colaboradores encontraron en el 2008 muestras de Panstrongylus herreri que presentaron una banda ITS-2 de un tamaño 960pb en los departamentos de Cajamarca y Amazonas, dicho tamaño de banda también fue encontrado en las muestras obtenidas en nuestro estudio, en los departamentos de Trujillo y Ucayali respectivamente.

El año 2017 se estableció, por primera vez, la presencia de Panstrongylus lignarius, también conocido como Panstrongylus herreri, en el estado de Rondonia, Brasil, cuya aparición era preocupante, porque se encontró que esta especie es-

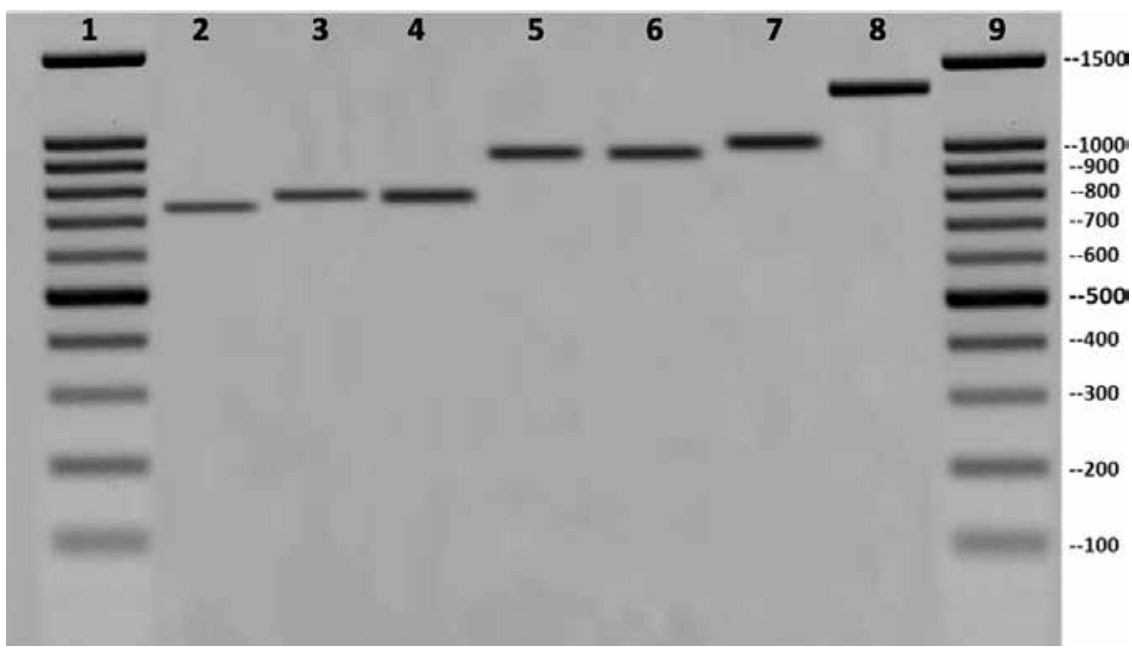

Figura 1. Amplificación del ITS-2: línea 1 y 9, marcador de peso molecular de 100pb; línea 2: Panstrongylus herreri (Bagua) 750pb; línea 3: Panstrongylus herreri (Cajabamba) 800pb; línea 4: Panstrongylus herreri (Cajamarca) 800pb; línea 5: Panstrongylus herreri (Ucayali) 960pb; línea 6: Panstrongylus herreri (Trujillo) 960pb; línea 7: Triatoma infestans-1000pb; línea 8: Rodnius sp.-1300pb. taba infectada naturalmente con Trypanosoma cruzi y había evidencia de sus capacidades de encontrarse localizada en otros países de América del Sur ${ }^{(16)}$. Por su parte, Ribero ${ }^{(17)}$ y colaboradores reportaron la presencia de $P$. lignarius ( $P$. herreri) en el estado de Acre, zona limítrofe con el departamento de Madre de Dios.

Se ha reportado que Panstrongylus herreri es un vector principal de la enfermedad de Chagas, y su éxito como vector se debía a su capacidad para establecer colonias domiciliadas, concluyéndose que, a pesar de haberse detectado una disminución en las tasas de oviposición, el potencial de P. herreri como vector de la enfermedad de Chagas en ambientes distintos del Amazonas debe ser considerado ${ }^{(18)}$.

Por su parte, Nevoa, Mendes, da Silva, Soares, Oliveira, Ribeiro ${ }^{(19)}$ en su artículo científico establecieron que los triatominos eran artrópodos hematófagos vectores de Trypanosoma cruzi, el agente causante de la enfermedad de Chagas

Además, se ha establecido que Panstrongylus lignarius, considerado uno de los triatominos más versátiles porque podía parasitar a diferentes hospederos, se encontraba en diferentes hábitats y países, tenía un comportamiento selvático, peri doméstico y doméstico, y era un vector muy importante de la transmisión de enfermedad de Chagas, especialmente en el Perú ${ }^{(19)}$.

El género Panstrongylus se ha localizado con denominaciones sinónimas en diversas partes del Perú; y mediante los resultados de esta investigación, se ha establecido al $100 \%$ que las muestras obtenidas fueron Panstrongylus herreri. Debido a su gran capacidad de adaptación, es posible ver su movimiento en la zona norte del Perú, Trujillo y Ucayali, y en otras zonas de Sudamérica, Brasil principalmente.

Mediante la caracterización molecular, se demostró que mediante el marcador molecular ITS-2 del ADN ribosomal, se pudo observar 3 patrones diferentes: 960pb; 800pb; 750pb. De los cuales solo el patrón 960pb era el primero en ser reportado en los departamentos de Cajamarca y Amazonas, y en este estudio dicho patrón se encontró en los departamentos de Trujillo y Ucayali. 


\section{AGRADECIMIENTOS}

Al equipo técnico y profesional del Laboratorio de Serología y Bioquímica Parasitaria del Instituto de Investigación Daniel Alcides Carrión, Facultad de Medicina UNMSM, por el procesamiento de las muestras.

\section{REFERENCIAS BIBLIOGRÁFICAS}

1. Guillén Z, Cáceres I, Elliot A, Ramírez J. Triatominos del norte peruano y su importancia como vectores de Trypanosoma spp. Revista Peruana de Entomología. 1988; 31(1):25-30.

2. Cuba C, Abad-Franch F, Roldán J, Vargas F Pollack L, Miles M. Los triatominos del norte del Perú, con énfasis en la ecología e infección por tripanosomas de Rhodnius ecuadoriensis (Triatominae). Mem. Inst. Oswaldo Cruz. 2002; 97 (2): 175-183. DOI: https://doi.org/10.1590/S007402762002000200005

3. Marin, E, Santillan, R, Cuba C, Jurberg J, Galvão C. Intra-domiciliary capture of Panstrongylus rufotuberculatus (Champion, 1899) (Hemiptera, Reduviidae, Triatominae) in Piura, Peru. Cadernos de saúde pública. 2007;23(9):2235-8. DOI: 10.1590/S0102-311X2007000900031

4. Solís H, Huamán A, Ferrer A, Tarqui K, Fajardo N, Rojas $\mathrm{M}$, et al. Comunicación preliminar sobre la presencia de Trypanosoma cruzi en departamentos del norte y nororiente del Perú. An. Fac. med. 2012; 73 (1): 43-46.

5. Cáceres A, Troyes L, Gonzáles-Pérez A, Llontop E, Bonilla C, Murias E, et al. Enfermedad de chagas en la Región Nororiental del Perú. I. Triatominos (Hemiptera, Reduviidae) presentes en Cajamarca y Amazonas. Rev. perú. med. exp. salud pública. 2002;19(1):17-23.
6. Elliot A, Cáceres I, Guillén Z, Nakashima I. Identificación de los chinches triatominos (Hemiptera Reduviidae) conocidos del Perú. Rev. Peru Entomol. 1988;31(1):18-20.

7. Marcilla A, Bargues MD, Ramsey JM, MagallonGastelum E, Salazar-Schettino P, Abad-Franch F, et al. The ITS-2 of the nuclear rDNA as a molecular marker for populations, species, and phylogenetic relationships in Triatominae (Hemiptera: Reduviidae), vectors of Chagas disease. Mol Phylogenet Evol. 2001;18(1):136-142. DOI: 10.1006 mpev.2000.0864

8. Marcilla A., Bargues M, Abad F., Panzera F., Carcavallo R., Noireau F. et al. Nuclear rDNA ITS2 sequences reveal polyphyly of Panstrongylus species (Hemiptera: Reduviidae: Triatominae), vectors of Trypanosoma cruzi. Infect Genet Evol; 2002; 1(3): 225-35.

9. Ancca J, Pinto J, Vega S, Cáceres A, Náquira C. Caracteristicas morfométricas, genéticas, alimenticias y vectoriales de Panstrongylus herrer procedentes de Jaén (Cajamarca) y Cajaruro (Amazonas), Perú. Rev. perú. med. exp. salud pública. 2008;25(1):17-25

10. Cabrera CR. Enfermedad de Chagas o tripanosomiasis americana. En: Suarez OL, Beingolea ML, Nakamoto TI, Cabrera CR, compiladores. Protocolos de vigilancia epidemiologica. Parte I, 2da ed. Lima: Dirección General de Epidemiologia, Ministerio de Salud; 2006: pp. 89-104.

11. Bargues MD, Klisiowicz DR, Panzera F, Noireau F, Marcilla A, Pérez R, et al. Origin and phylogeography of Chagas disease main vector Triatoma infestans based on nuclear rDNA sequences and genoma size. Infection, Genetics and evolution. 2006; 6(1): 46-62. DOI: https://doi.org/10.1016/j. meegid.2005.01.006

12. Borges E, Pires H, Barbosa S, Nunes C, Pereira M, Romanha A, Diotaiuti L. Genetic variability in Brasilian triatomines and the Risk of domiciliation. Mem. Inst Oswaldo Cruz. 1999 94(1):371-373. DOI: https://doi.org/10.1590/ S0074-02761999000700072
13. Lent $\mathrm{H}$, Wygodzinsky P. Revision of the triatominae (hemiptera, reduviidae), and their significance as vectors of Chagas' disease. bull. am. museum nat. hist. 1979;163:179-460.

14. Fraga J, Rodríguez J, Fuentes $O$, Fernández A, Castex M. Optimización de la técnica de ADN Polimórfico amplificado al azar (RAPD) para su utilización en la caracterización genética de triatominos cubanos; 2005. Revista del Instituto de Medicina Tropical de Sao Paulo. 2005;47(5): 295-300. DOI: https://doi.org/10.1590/S003646652005000500010

15. Wygodzinsky P. Sobre Pantrongylus del Perú, con la descripción de una nueva especie (Triatominae, Reduviidae, Hemiptera). An. Inst. Med. Reg. Tucumán. 1948;2:197-208.

16. Terassini FA, Stefanello C, Aranha LM, Ulises de Oliveira D. Primer informe de Panstrongylus lignarius, Walker, 1873 (Hemiptera, Reduviidae, Triatominae), en el estado de Rondônia, Brasil. Rev. Soc. Bras. Medicina. Trop. 2017;50(4):547549. DOI: https://doi.org/10.1590/0037-86820048-2017

17. Lima M, Vieira de Souza G, Lunier de Sousa J, Portela F, Aranha LM. First report of Panstrongylus lignarius (Walker, 1873) (Hemiptera: Reduviidae: Triatominae) in the State of Acre, Brazil. Rev. Soc. Bras. Med. Trop. 2019;52: e20180307. DOI: https:// doi.org/10.1590/0037-8682-0307-2018

18. Franzim E, Tays M, Marfil ACB, Vinicius M, Rodrigues $V$, Sales-Campos H, et al. El desarrollo de Panstrongylus herreri en condiciones ambientales fluctuantes. Rev. Soc. Bras. Medicina. Trop. 2017;50(1):121-125. DOl: https://doi. org/10.1590/0037-8682-0250-2016

19. Nevoa J, Mendes M, da Silva M, Soares S, Oliveira C, Ribeiro J. An insight into the salivary gland and fat body transcriptome of Panstrongylus lignarius (Hemiptera: Heteroptera), the main vector of Chagas disease in Peru. PLoS Negl Trop Dis. 2018; 12(2): e0006243. DOI: https://doi.org/10.1371/ journal.pntd.0006243 